\title{
0 Site-specific Como Dramaturgia do Espetáculo
}

\author{
José Jackson Silva \\ Universidade Federal do Rio Grande do Sul - UFRGS, Porto Alegre, Brasil \\ E-mail: jacksontea@gmail.com
}

\section{Resumo}

O presente artigo apresenta uma questão que parece bastante sugestiva quando se investiga o teatro contemporâneo: é possível consideramos o espaço cênico como dramaturgia no teatro site-specific? A fim de responder provisoriamente tal indagação, nos detemos sobre a encenação do espetáculo Rebola, concebido pelo coletivo cênico Teatro da Queda, traçando um paralelo com os conceitos de site-specific e seus principais fundamentos que, via de regra, problematizam a gênese da encenação.

Palavras-chave

Teatro. Site-specific. Espaço Cênico.

Dramaturgia. Encenação.
Abstract

The present article presents an issue that seems very suggestive when one investigates contemporary theater: is it possible to consider the scenic space as dramaturgy in the site-specific theater? In order to respond provisionally to such inquiry, we dwell on the performance of the Rebola spectacle, conceived by the scenic collective Teatro da Queda, drawing a parallel with the concepts of site-specific and its main foundations that, as a rule, problematize the genesis of the staging. Keywords

Theater. Site-specific. Scenic Space.

Dramaturgy. Staging. 
Num sentido mais recente, dramaturgia tende a ultrapassar o âmbito de escrita e estudo do texto dramático, para englobar texto e realização cênica. De modo tal, que dramaturgia pode designar tanto o texto dramático quanto os meios cênicos empregados na encenação, como nos lembra Pavis (1998). Concepção esta que perpassou todo o século $\mathrm{XX}$, sendo problematizada nas vanguardas artísticas, desenvolvidas nas teorias do teatro épico de Brecht, e concretizada com o desenvolvimento de formas não-dramáticas que se elaboraram sob a influência da Dança, da Performance, da Instalação, etc., denominada por Lehmann de teatro pós-dramático.

Partindo desta constatação, vamos ao encontro de uma questão que nos parece bem sugestiva ao tratarmos a poética site-specific e a potência que essa prática artística tem em revelar novos agenciamentos para os componentes da encenação: é possível consideramos o espaço cênico como dramaturgia na poética site-specific?

Aqui temos já um paradoxo funcionando, pois esta pergunta nos coloca, imediatamente, diante da perspectiva de assumir o espaço cênico como algo mais do que a área reservada a apresentação do espetáculo, rompendo, assim, com a ideia fixa e imutável das arquiteturas teatrais e das convenções por elas impetradas, desobrigando o espaço de ser apenas uma plataforma de exposição, para considerá-lo um agente do jogo cênico e da teatralidade.

Neste raciocínio, temos que o espaço cênico, além da arquitetura teatral, define-se a partir de dois outros níveis: a cenografia e a ação cênica, que, segundo Francisco Javier (1998), determinam, basicamente, o tipo de comunicação que o espetáculo busca com seu público. Sendo a cenografia a ambientação do drama, se concretiza a partir das preferências e dos elementos cenográficos propostos na poética de cada trabalho cênico, e estes, por sua vez, atribuem determinadas ações cênicas que se efetivam a partir das suposições encontradas no texto dramático.

Constatando a sujeição do espaço cênico à literatura dramática, poderíamos concluir nossas reflexões e assegurar essa afirmativa submissão do espaço cênico ao texto dramático, no qual o primeiro somente existe após a concretização do segundo. Mas não sejamos precipitados, porque o conceito e utilização do espaço cênico, assim como o de dramaturgia, também passou por uma transfiguração: da definição de um local fixo, pré-determinado pela arquitetura, circunscrito pelas suas tipologias históricas, para se concentrar na expansão dos limites entre o espaço da encenação e as fronteiras materiais e virtuais presentes no ato da fruição.

Acontece que, ao vincular-se ao acontecimento cênico, o espaço passou a reorganizar os agentes do espetáculo, do antigo modelo cartesiano (espaço para exibição de um evento cênico planejado diante de um público), para um ambiente de experiências (lugar do gesto compartilhado entre atores e público), no qual compreende o espetáculo como pertencendo àquele espaço, e, se o espaço muda, a inter-relação dos agentes também é modificada.

Esta interdependência estabeleceu as bases do que posteriormente incidiria na concepção de site-specific, conceito que deriva das práticas vanguardistas das artes plásticas, e nos fornece um horizonte amplo de intersecções para considerarmos nossa especulação teórica acerca da dramaturgia do espaço no teatro site-specific, que dialoga de perto com as acepções do teatro pós-dramático.

Como terminologia discursiva, a arte site-specific localiza-se no fim da década de 1960, em decorrência de uma reação dos artistas plásticos às condições de exposição, circulação e acesso das obras. Nesta ocasião passaram a denunciar a não neutralidade do 
espaço institucional e a recusa de um modelo de mercantilização da arte, como aponta Miwon Kwon (2004), ao enfatizar o engajamento dos artistas minimalistas na proposição de trabalhos fora das galerias, materializados no espaço comum e ordinário do cotidiano em contraposição ao idealismo modernista:

A arte site-specific tomou o "site" por
sua materialidade real, realidade tangí-
vel, composta por uma singular combi-
nação de elementos físicos constituti-
vos: comprimento, profundidade, altura,
textura e formato das paredes e salas;
escala e proporção de praças, edifí-
cios ou parques; condições existentes
de iluminação, ventilação, padrões de
trânsito, características topográficas
particulares. (KWON, 2004, p. 167).

Os trabalhos em site-specific em sua primeira formação, diz Miwon, iniciou-se com um desafio epistemológico de realocar o significado interno do objeto artístico para as contingências de seu contexto. E esta seria, precisamente, a maneira através da qual a prática do site-specific viria a radicalizar a relação com o local onde o trabalho artístico é realizado e encontrou uma definição-chave nas palavras do escultor Richard Serra:

Tilted Arc foi encomendada e projetada para uma localização específica: a Federal Plaza. É um trabalho site-specific e como tal não é para ser realocado. Removê-lo é destruir a obra. Trabalhos site-specific lidam com componentes ambientais de determinados lugares. Escala, tamanho e localização dos trabalhos site-specific são determinados pela topografia do lugar, seja esse urbano ou paisagístico ou clausura arquitetônica. Os trabalhos tornam-se parte do lugar e reestruturam sua organização tanto conceitual quanto perceptual. (SERRAS apud KWON, 2004, p. 167).

A partir deste entendimento, a utilização do espaço na composição do trabalho artístico muda, de uma definição de suporte em um local fixo, pré-determinado - em galerias e museus, como garantia existencial e validação enquanto trabalho artístico - para se concentrar nos limites entre o espaço interior e exterior da obra, ao assumir o lugar de exposição como parte indivisível e amplamente influente na obra. Compreende-se, então, que a obra pertence ao seu site, se o site muda, a inter-relação entre os objetos, contextos e pontos de vista também são modificados.

Concomitante a esse movimento na direção da desestetização e progressiva desmaterialização do espaço de exposição, a arte site-specific adota estratégias que são ou agressivamente antivisuais - informativas, textuais, expositivas, didáticas - ou imateriais como um todo (gestos, eventos, performances limitadas pelo tempo). Por essa razão, o significado do minimalismo para a ideia de site-specific, não é simplesmente uma equação do uso do espaço que visa afetar a recepção, vai além, como observa Michael Fried (1968), ao argumentar que:

A experiência literal da arte minimalista
de um objeto em situação que, virtual-
mente por definição, inclui o espectador
e o submete a uma percepção do tempo
e do espaço na experiência da obra, en-
tra em um campo que "se situa no entre
artes", onde as artes visuais se degene-
ram aproximando-se da condição do te-
atro. Ao enfatizar o ato transitório e efê-
mero da fruição, o minimalismo entra no
domínio essencialmente teatral e perfor-
mativo. (FRIED apud KAYE, 2006, p. 3).

Esta constatação, como sinal dos tempos, baliza o caráter de realização performativa sob a qual as artes plásticas foram submetidas em meados dos anos de 1940 com as práticas da action painting e no body art, como ocorreria, posteriormente, também nas esculturas de luz e videoinstalações, entre outros. Nelas, ou bem o artista se apresentava a si mesmo perante o público na ação de pintar e exibir seu corpo, que previa- 
mente havia caracterizado como um modo particular de criação artística, ou bem convidava o observador a se mover pela exposição e a interagir com os elementos expostos, enquanto outros visitantes observavam.

Prontamente, visitar uma exposição de artes se converteu, em muitos casos, em um testemunho da execução do artista, ou na participação do público interagindo com a obra numa realização performativa que muitas vezes o convocava a experimentar as espacialidades criadas nos distintos espaços onde o trabalho estava exposto. Assim, "não se tratava de entender a performance como um texto a ser lido e compreendido racionalmente, mas de experimentá-la e de enfrentar a experiência naquele local singular, repleto de escapismos e significados" (FISCHER-LICHTE, 2011, p. 38).

Esse impulso performativo que acometeu todas as linguagens artísticas a partir de 1960 estabeleceu os novos paradigmas, no qual as fronteiras entre as distintas artes ficaram cada vez mais tênues, e com uma tendência a criação não de obras de arte, mas de acontecimentos, que progressivamente convergiram para a Arte da Performance, haja visto, por exemplo, a criação e concepção dos quadros de Jackson Pollock e, sobretudo, dos Happening de Allan Kaprow, para o qual a realização dos seus trabalhos não adquire um status de objeto artístico, mas um acontecimento não repetível, através da presença conjunta dos artistas e público em um lugar peculiar que suscita tal relação.

Vê-se bem, a partir de então, que os vetores espaciais que reorientaram a experiência artística das artes visuais de um local neutro, fixo e institucionalizado, para um espaço fluido interconectado e indivisível na experiência artística, afetaram diretamente na criação da obra, ao oferecer ao espectador a possibilidade de localizar seu próprio espaço no trabalho artístico, a ponto de conduzir a linguagem das artes visuais para um hiato semântico ao se aproximar da linguagem cênica e da performatividade inerente ao espaço praticado.

Assim como nas artes plásticas, no teatro também surgiram e constantemente surgem projetos de encenações motivados por uma ativação do espaço. Mas foi somente na década de 1980, segundo Fiona Wilkie (2004), que o termo site-specific passou a ser usado em larga escala no teatro inglês, e, desde então, tem sido matéria de pesquisa e experimentos práticos de vários criadores que se detém sob esta modalidade para tentar definir suas particularidades conceituais e também metodológica, uma vez que estão inseridos dentro da Performance Art, que por si, extrapola os limites das convenções teatrais para o uso do espaço cênico.

Diante da tarefa de articular reflexões que se aproxima de uma definição de teatro site-specific, Patrice Pavis, em seu dicionário, postulou:

Este termo se refere à encenação e espetáculos concebidos a partir e em função de um local encontrado na realidade (e, portanto, fora dos teatros estabelecidos). Grande parte do trabalho reside na procura de um lugar ou impregnado por uma forte atmosfera: barracão, fábrica desativada, parte de uma cidade, casa ou apartamento. A inserção de um texto, clássico ou moderno, neste local descoberto the confere uma nova iluminação, uma força insuspeitada e instala o público numa relação completamente diferente com o texto, o lugar e a intenção. Este novo quadro fornece uma nova situação de enunciação que, como na land art, faz-nos redescobrir a natureza e a disposição do território e dá ao espetáculo uma ambientação insólita que constitui todo seu encanto e força. (PAVIS, 1998, p. 127). 
Primeiramente, nessa observação de Pavis, percebemos que o teatro site-specific opera em função do espaço encontrado na realidade tangível do nosso cotidiano: garagens, galpões, igrejas, fábricas desativadas, apartamentos, parques, etc., que são apropriados pelos artistas como espaço cênico para as suas criações. Com isso, descarta-se qualquer vinculação entre a prática do teatro site-specific como o monumento arquitetônico idealizado para a exposição dos trabalhos cênicos e as convenções que dele emergem.

$\mathrm{Na}$ leitura do autor a utilização desses espaços favorece, ainda, uma ambientação incomum para a peça e oferece um meio para abrigar uma leitura excepcional de um texto dramático, que, por sua vez, desencadeia diversas relações que a peça possa vir a estabelecer com o público ao tomar a natureza do espaço como enunciado do espetáculo.

Contudo, vale ressaltar que, no teatro site-specific, o local selecionado como espaço cênico não deve ser concebido como um pano de fundo interessante e desinteressado no significado da construção do espetáculo, como as palavras de Pavis podem sugerir, nem tampouco, uma ilustração/ambientação incomum para um texto dramático, porque, igualmente às artes visuais, as especificidades do local vinculam-se à encenação por meio dos processos significantes que do próprio espaço emergem, sejam eles narrativos, simbólicos ou estruturais, que estarão presentes de alguma forma na constituição do espetáculo.

Deste modo, qualquer possibilidade de um espaço neutro na encenação site-specific torna-se uma incongruência abissal, visto que estas proposições teatrais se valem da própria identidade do local para compor o espetáculo, seja como especulação narrativa, seja como símbolo para alguma questão que o espetáculo esteja debatendo, seja, ainda, como contraponto material para o discurso da peça.
Porém, é pouco provável ser um quadro em branco sobre o qual os agentes do espetáculo irão operar e aplicar suas técnicas, pois, como bem definiu Lehmann: "o teatro específico ao local procura uma arquitetura ou uma localidade não tanto porque o "local" corresponda particularmente bem a um determinado texto, mas, sobretudo, porque se visa que o próprio espaço seja trazido à fala por meio do teatro" (LEHMANN, 2007, p. 281).

Compreende-se, então, que a encenação derivada desse conceito decide por um espaço que tenha a possibilidade de responder e interrogar uma série de preocupações que o circundam, representando escolhas formais e estéticas, visto que, estamos no campo das artes, mas, igualmente políticas e discursivas pela própria concretude e significados dos espaços cotidianos performatizados neste tipo de encenação.

Do mesmo modo, ao se constituir a partir de um espaço real do cotidiano com uma função completamente distinta dos espaços dados às artes cênicas, a encenação site-specific leva o espaço cênico a operar em um campo dimensional ambíguo, que por um lado se sabe construindo uma ficção ao fazer uso das ferramentas e códigos que a linguagem teatral Ihe fornece; por outro lado, está inserido dentro de um espaço funcional da realidade concreta e tangível da sociedade e suas imensas complexidades.

Logo, essas propostas cênicas acabam não criando uma representação do real, nem tampouco uma interpretação de realidade, mas criando uma intervenção sobre o real, característica permanente no teatro contemporâneo, segundo José Sánchez (2007). De maneira tal, que tirar a encenação do espaço no qual ela foi concebida é destruir a obra, pois as características inerentes àquele espaço são únicas e estão imbricados diretamente na estrutura do espetáculo. Ou, como bem sublinhou André 
Carreira, ao se deter sobre o que chamou de "teatro de invasão", que dialoga de perto com o conceito que estamos tratando:

Se estiver pensando a cidade apenas
como imagem arquitetônica, se não se
explora a capacidade de fazer com que
os novos espaços penetrem a cena, por-
tanto, estará se reforçando exclusiva-
mente sua função cenográfica. A mobi-
lidade não põe fim à originalidade, nem
corrói a ideia do efêmero da cena. Essa
re-fabricação que também é comum
nas obras de site-specific, re-contextu-
aliza o trabalho mais conceitual, sem-
pre e quando se descobrem caminhos
que estabeleçam novos diálogos com
a cidade (CARREIRA, 2017, p. 104).

Ratificando este raciocínio, Nick Kaye (2006), ressalta que ao tentarmos traçar uma definição para teatro site-specific, devemos recorrer necessariamente à própria origem do conceito, pois ele estimula uma investigação mais ampla de como podemos entender o espaço como sendo menos fixo ou menos especificamente geográfico e mais virtual. Nas suas palavras:

Não é apenas fornecer um modelo de relacionamento de um não-espaço em espaço cênico, mas no contexto de uma definição transitória de espaço, a especificidade do espaço em si. É nesse contexto que a arte site-specific frequentemente trabalha para problematizar as oposições entre o espaço e a obra. É também nesta oposição que as abordagens das artes visuais e da arquitetura percebem o espaço, ou podem ser lidas, através do termo performance (KEYE, 2000, p. 19).

Neste entendimento, o autor sugere que o espaço deva ser fundamentado a partir do entendimento das especificidades (virtualidades) do espaço, que são transitórias e efêmeras, mais do que pelo perímetro geográfico (fixo e imutável) que o espaço ocupa.

Para chegarmos a um bom termo, sugere que devemos recorrer ao entendimento das artes visuais sobre a prática do site-specific, pois, dentre outras coisas, estas tratam as preocupações estéticas, históricas e materiais como questões secundárias, ao priorizar o engajamento do artista com o cotidiano do local encontrado e suas diversas formas identitárias, o que, por sua vez, provoca uma ligação com a obra em termos não apenas físicos, mas virtuais, determinados pelas próprias características do espaço.

Neste sentido, Miwon Kwon (2004) identifica três paradigmas que definem as especificidades comuns às práticas site-specific: 0 fenomenológico; o social e o discursivo, que se interpenetram pela possibilidade de conceber o espaço como algo mais do que as características topográficas, antes, por toda maIha que, em ressonância, rege esse espaço.

Em seu entendimento o espaço fenomenológico estaria localizado no lugar literal concreto e significante da realidade (fábrica, apartamento, garagem, igreja, etc.), que o teatro, fazendo uso como espaço cênico, estabelece as relações da experiência artística por ele desencadeada; Já o espaço crítico social, inclui outra camada à ideia de espaço, pautando, especialmente, a criação do trabalho sob os vetores sociais e políticos, bem como, das convenções engendradas naquele espaço em que os artistas passam a se endereçar no momento da instalação do trabalho, para além dos aspectos físicos do espaço.

No que tange ao espaço discursivo, o trabalho estaria descolado do local literal, passando a se ocupar de um assunto mais abrangente, um discurso que paira sob o espaço, seja ele ecológico, racial, de gênero ou outras formas identitárias relevantes a serem debatidas e suscitadas naquele espaço. Como assegura Kwon:

As obras não querem mais ser um substantivo/ objeto, mas um verbo/processo, provocando a acuidade crítica (não somente física) do espectador no que con- 
cerne, inclusive, às condições ideológicas dessa experiência. O que significa que o site deve ser estruturado (inter) textualmente mais do que espacialmente, e podem ser estruturados para serem experimentados transitivamente, uma coisa depois da outra, e não como simultaneidade sincrônica. Essa transformação do site textualiza espaços e espacializa discursos (KWON, 2004, p.111).

Nestes apontamentos, a especificidade do espaço acaba por gerar uma certa polissemia e se comporia por meio dessas esferas de espaços que se afetam mutuamente e estabelecem um salto conceitual crucial na redefinição da experiência artística, subscrita pelos espaços imbricados nas obras.

Como exemplo para essa fundamentação, podemos pensar a dramaturgia do espetáculo Rebola, do coletivo soteropolitano Teatro da Queda, encenado em 2016, que nos ajuda a entender as camadas de espaços das quais Kwon se refere.

Figura 1: Espetáculo Rebola, encenação do Teatro da Queda

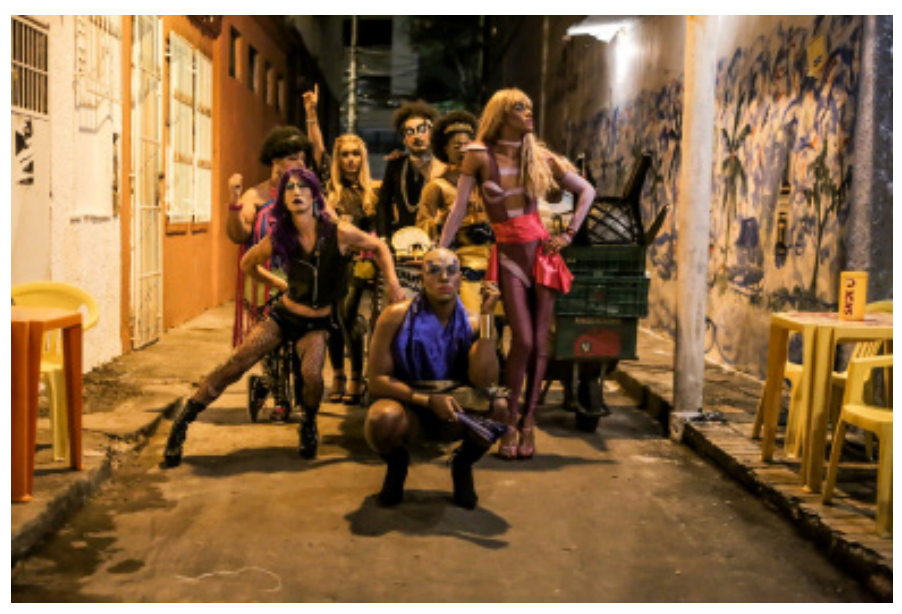

Foto: Andréa Magnoni

Este espetáculo foi concebido para ser apresentado dentro de um bar, um bar comum, daqueles que grande parte dos cidadãos vão para bebericar, conversar e se distrair das obrigações diárias. Mas este, em especial, se localiza no "beco dos artistas", um espaço histórico de resistência da comunidade LGBT da cidade de Salvador, no estado da Bahia.

Como proposta cênica, a encenação se desenvolveria neste bar, onde os frequentadores seriam assumidos como espectadores, quando, em um dado momento da noite, seriam interpelados pela ficção, ao serem impelidos por um rompante intempestivo de um dos atores a fechar um dos bares dessa localidade, alegando que está falido e que naquela noite seria a última vez que o estabelecimento estaria de portas abertas. ${ }^{10} \mathrm{En}$ clausurando consigo um espaço de existência e exibição para os shows das Drag queens, da mesma maneira que, encerraria as atividades laborais de todas as funcionárias, que ficariam sem emprego, neste país que está sempre pronto a oferecer a prostituição como única opção laboral para esses cidadãos.

Neste contexto, o espaço cênico 'bar' seria a primeira camada sugerida por Kwon (a fenomenológica) o espaço concreto da experiência proposta pela encenação. A segunda camada diz respeito ao significado sociopolítico de um bar especial para o público LGBT para a própria cidade, uma vez que a cidade de Salvador é uma das cidades que mais matam LGBT no mundo, mesmo sendo um dos principais destinos do turismo gay do Brasil. Neste flagrante contrassenso, se instala um conflito sociopolítico importante para aquela comunidade que o espetáculo se apoderou, em ressonância, para refletir sobre a própria cidade, incluindo nessa perspectiva, a especulação imobiliária, dado que o 'beco dos artistas' está localizado em uma área nobre da cidade.

\footnotetext{
10 Vale ressaltar que a abrupta interferência dos atores na rotina no bar não deve ser confundida como o "teatro invisível" de Augusto Boal, pois, desde o princípio, os espectadores sabem que estão ali para presenciar um espetáculo teatral, e mesmo que houvesse algum frequentador desavisado no bar, rapidamente percebia a espetacularização do ambiente, diferentemente do "teatro invisível", onde o anonimato da linguagem é a base da sua constituição.
} 
Figura 2: Espetáculo Rebola, encenação do Teatro da Queda

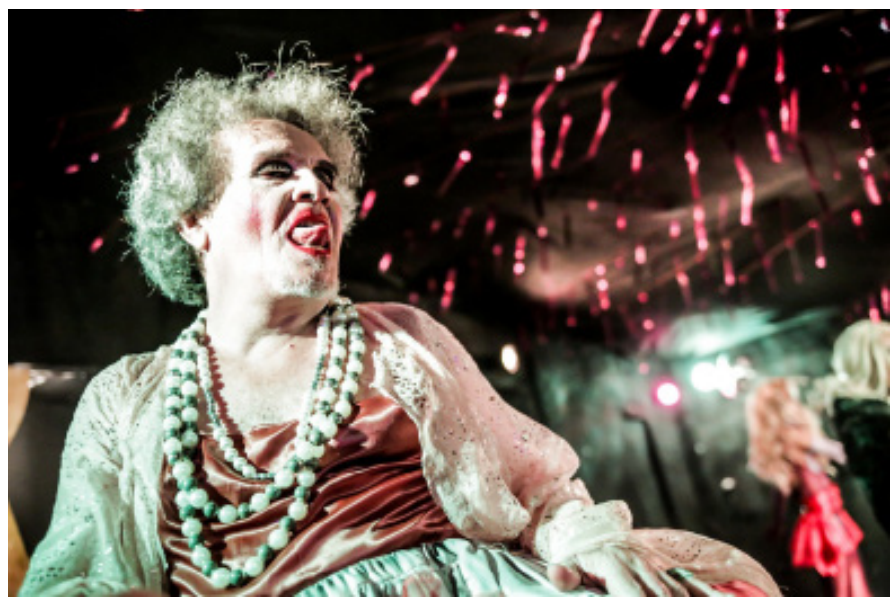

Foto: Andréa Magnoni

A terceira camada identificada nesta encenação (a discursiva) pode ser observada na própria motivação do grupo em refletir sobre o descaso da sociedade em considerar as pessoas LGBT como cidadãos, mesmo quando são promotoras dos seus sustentos e/ou viabilizam vagas de empregos, gerando renda para a cidade, lhe são negadas o acesso aos direitos sociais, dentre eles, os bens culturais e liberdade de expressão.

A história do lugar (beco dos artistas), nesse exemplo, é a estrutura central da encenação, posto que, confia sua concepção, produção e recepção à complexa convivência material do espaço (instalações, histórico e contexto) como a imaterialidade inerente à linguagem artística (artificial, imagética, efêmera), que se sobrepõem e interpenetram-se a partir daquilo que antecede a obra e aquilo que é a obra: o passado e o presente, artificialmente construído, com uma presença material do espaço que não consegue ser suplantado pelo trabalho artístico, muito pelo contrário, a dramaturgia da encenação se desenvolve e fortalece pelos agenciamentos do próprio espaço.

Contribuindo, assim, para uma narrativa passível de múltiplas leituras e significados, como bem entende Mike Pearson (2010), ao defender que os espetáculos site-specific são inseparáveis de seus espaços, pois só conseguem ser inteligíveis a partir daquele contexto no qual, ou para o qual, foram criados.

\section{Figura 3: Espetáculo Rebola, encenação do Teatro da Queda}

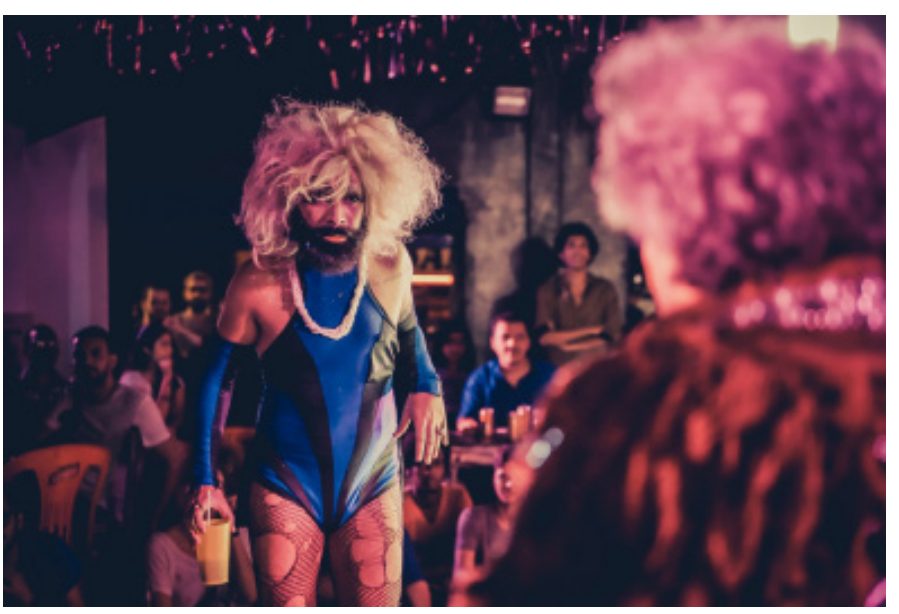

Foto: Andréa Magnoni

No espetáculo Rebola, evidencia-se que a criação da dramaturgia parte de procedimentos de criação distinto dos tradicionais (não se espera a produção literária de um autor pronta a ser levada à cena), aqui a dramaturgia, em processo, se desenvolve diante da possibilidade de um recinto do cotidiano servir como mote especulativo, e espaço cênico, fator que acaba por instaurar um problema processual que será a base de toda estrutura da dramaturgia do espetáculo, instituída a partir do espaço, ou para ele.

Esta formulação, como bem entendeu Laura Moreira, revela que as dinâmicas que animam a construção das dramaturgias contemporâneas estão em constante diálogo com as proposições cênicas de todos os agentes do espetáculo, sem se ater a horizontalização do processo criativo, antes ao hibridismo das iniciativas criativas e criticas que se acomodam segundo dinâmicas específicas que os orientam (2012, MOREIRA apud NETO, 2016, p.158).

Não por acaso, os criadores do espetá- 
culo Rebola relatam que o principal procedimento de criação foi a imersão no espaço, para traçar um mapeamento e uma escuta do espaço, buscando perceber suas dinâmicas e possibilidades expressivas, antes de definir qualquer interação ou comentário sobre ele.

Neste procedimento, o mapeamento, convém como instrumento de localização e identificação do espaço para o contexto ao qual pertence; já a escuta, para se perceber os vetores de comunicação, significados e percepções presentes no espaço, seus bens simbólicos e referências comuns. Ou seja, para criar a dramaturgia do espetáculo nesta poética, os criadores precisaram se inserir dentro do espaço para extrair dele as zonas de intersecção que foram exploradas pela ficção.

Este procedimento, portanto, difere da cultura teatral baseada na literatura dramática que, em geral, demanda atenção ao espaço apenas como veículo de exposição do espetáculo, principiando seus processos criativos pelos artifícios tradicionais da linguagem: literatura dramática, especulação temática, investigação técnica dos atores e personagens, etc., que ao serem instituídos como início metodológico, prontamente serão explorados em um espaço mais neutro possível, as salas de ensaio.

As encenações em site-specific não ignoram essas ferramentas metodológicas utilizadas largamente no teatro, muito pelo contrário, as utilizam de maneira dialógica com as especificidades que constituem os espaços, nas quais os criadores se agarram ou se esbarram toda vez que desenvolve um trabalho sob estes termos, seja para conversar, questionar ou mesmo negar o espaço perante as questões sociopolíticas, econômicas e discursivas inerentes àquela comunidade na qual o espaço está inserido.

Novamente aqui, a escolha do local, possivelmente, não tenha a ver com padrões estético ou tipografias históricas, mas do desejo pessoal em investigar um lugar dado da realidade material como lugar de uma ficção, de modo tal, que possa imprimir sobre ele uma interpretação conceitual e estética a partir das próprias características que os constitui.

Imediatamente após esse gesto, todos os componentes da produção do espetáculo serão reestruturados para os fins pretendidos. Cabendo aos criadores da dramaturgia (seja ele o dramaturgista, o próprio encenador, ou elenco), decodificar o espaço e dialogar com as suas virtualidades, que, por sua vez, poderão mediar toda a concepção, produção e recepção do espetáculo, com a possibilidade, inclusive, do espaço contar sua própria história, como notamos no Rebola.

Figura 4: Espetáculo Rebola, encenação do Teatro da Queda

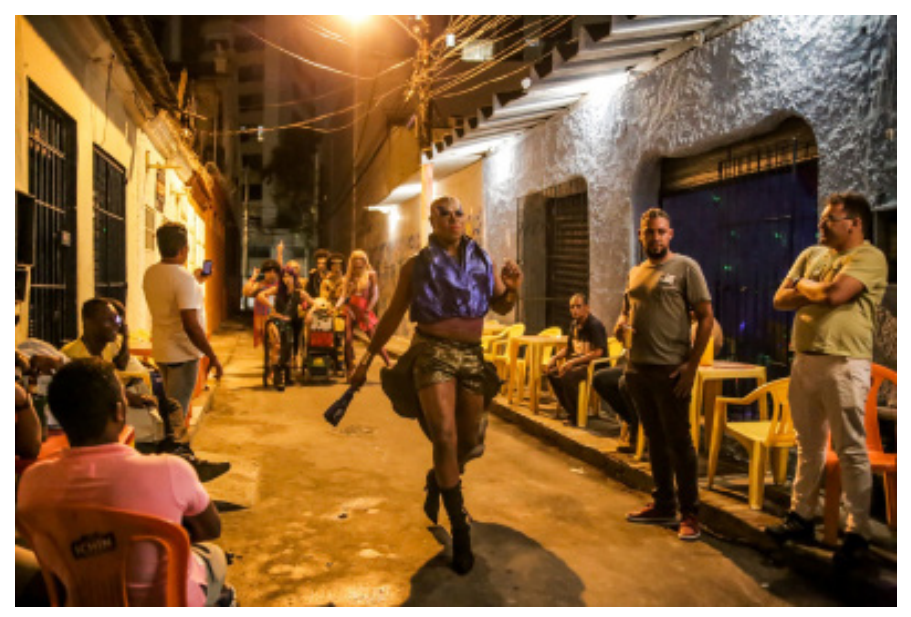

Foto: Andréa Magnoni

Nesta formulação, atores e espectadores compartilham da intimidade de uma experiência cênica em um espaço-tempo com características singulares, que, ao mesmo tempo que os aproxima, pode espelhar o estranhamento daqueles corpos alheios à realidade do espaço, e por isso mesmo, torná-los essenciais quando percebido sob novas lentes. Consequentemente, o site-specific como dramaturgia do espetáculo pode ser entendida como o espaço e suas circunstâncias. 
Por essa razão, entendemos que não se trata de questionar como as camadas do espaço são configuradas, mas sim de que forma o evento cênico se move através delas. $E$, justamente por isso, o espaço passa ser um dos agentes da dramaturgia, especialmente, quando suas estruturas e conjunturas são protagonistas, a ponto de ser o centro da criação e desenvolvimento do espetáculo, como no espetáculo Rebola.

Bibliografia

CARREIRA, André. Teatro de invasión: La ciudad como dramaturgia. Cordoba: documenta/escenicas ediciones, 2017.

FÉRAL, Josette. Teatro, teoria y prática: Más allá de las fronteras. Buenos Aires, Galerna, 2004.

FISCHER-LICHTE, Erika. Estética de lo performativo, trad. Diana González Martín. Madrid: Abada Editores, 2011.

JAVIER, Francisco. El espacio escénico como sistema significante: La renovación del espacio escénico. Editorial Leviatán, 1998.

KAYE, Nick. Site-Specific Art: Performance, place and documentación. Londres: Routledge, 2006.

KWON, Miwon. One place after another: Site-specific art and locational identity. London: The MIT Press, 2004.

LEHMANN, Has Thies. Teatro pós-drámatico. São Paulo: Cosac Naify, 2007.
NETO, Walter Lima Torres. Ensaio de cultura teatral. Jundiaí: Paco Editorial, 2016.

PAVIS, Patrice. Dicionário de teatro. São Paulo: perspectiva, 1998.

PEARSON, Mike. Site-specific performance. New York: Palgrave Macmillan. 2010.

SANCHÉZ, José Antonio. Prácticas de lo real en la escena contemporánea. Madrid: Visor, 2007.

SCHECHNER, Richard. Environmental theater. New York: Applause, 1994.

WILKIE, Fiona. Out of place: the negotiation of space in site-specific performance. Thesis of PHD. University of surrey school of arts, 2004.

Recebido: 24/04/2019 Aprovado: 22/10/2019 